\title{
Baja AISI 1006: Efek Suhu Pemanasan Terhadap Sifat Mekanik Dan Strukturmikro
}

\author{
Nasmi Herlina Sari ${ }^{* 1}$, Lalu Tumbuh Prasetya ${ }^{1}$, Agus Dwi Catur ${ }^{1{ }^{*}}$ \\ ${ }^{1)}$ Teknik Mesin Fakultas Teknik Universitas Mataram, \\ JIn. Majapahit No. 62 Mataram Nusa Tenggara Barat \\ Kode Pos: 83125, Telp. (0370) 636087; 636126; ext 128 Fax (0370) 636087 \\ Email: n.herlinasari@unram.ac.id \\ doi: https://doi.org/10.24843/METTEK.2018.v04.i01.p01
}

\begin{abstract}
Abstrak
Penyelidikan sifat-sifat dari baja AISI 1006 menggunakan suhu pemanasan masih sangat menarik untuk dikembangkan. Penelitian ini bertujuan untuk menyelidiki efek suhu pemanasan dan tempering terhadap sifat mekanik dan strukturmikro baja AISI 1006. Variasi suhu pemanasan yang digunakan adalah $850^{\circ} \mathrm{C}, 900^{\circ} \mathrm{C}$ dan $950^{\circ} \mathrm{C}$. Proses tempering dilakukan pada suhu $200^{\circ} \mathrm{C}$. Spesimen dibentuk mengikuti standar internasional untuk pengujian impak, kekerasan dan strukturmikro. Energi serap dan kekuatan impak ditentukan dengan menggunakan mesin uji impak, dan kekerasan baja diukur mengunakan mesin uji kekerasan Vickers. Selain itu, strukturmikro dari baja juga telah dianalisa menggunakan mikroskop metalografi. Hasil ini menunjukkan bahwa peningkatan suhu pemanasan dan tempering pada $200^{\circ} \mathrm{C}$ menurunkan nilai kekuatan impak dan penyerapan energi baja; sebaliknya, kekerasan baja meningkat; karena fase austenit berubah menjadi perlit dan sementit. Energi penyerapan dan kekuatan impak tertinggi diperoleh dari spesimen yang dipanaskan pada suhu $850^{\circ} \mathrm{C}$. Sementara itu, nilai kekerasan tertinggi diperoleh dari spesimen yang dipanaskan pada suhu $950^{\circ} \mathrm{C}$ dengan tempering $200^{\circ} \mathrm{C}$. Hasil ini diharapkan dapat memberikan data dan informasi bagi para peneliti dan industrialis dalam mengembangkan produk baja untuk berbagai aplikasi.
\end{abstract}

Kata kunci: Baja AISI 1006, perlakuan panas, tempering, energi serap, kekerasan, dan struktur mikro

\begin{abstract}
Investigation of the properties of AISI 1006 steel using the heating temperature is still very attractive for development. This study aims to determine the effect of heating and tempering temperature on mechanical properties and microstructure of AISI 1006 steel. Heating temperature variations used were $850^{\circ} \mathrm{C}, 900^{\circ} \mathrm{C}$, and $950^{\circ} \mathrm{C}$. The tempering process is carried out at $200^{\circ} \mathrm{C}$. The specimens are formed following international standards for impact, hardness and microstructure testing. Absorption energy and impact strength were determined by using impact machine, and the hardness of steel was investigated by hardness Vickers machine. Besides, the microstructure of steel was analyzed by microscope metallography. The results show that an increase in temperature of heating and tempering at $200^{\circ} \mathrm{C}$ decreases the value of impact strength and absorption of steel energy; in contrast, the hardness of steel increases; because of the austenite phase changes to pearlite and cementite. The highest absorption energy and impact strength were obtained from the specimens heated at $850^{\circ} \mathrm{C}$. Meanwhile, the highest hardness value was obtained from the specimens heated at $950^{\circ} \mathrm{C}$ with tempering at $200^{\circ} \mathrm{C}$. These results are expected to provide data and information for researchers and industrialists in developing steel products for various applications.
\end{abstract}

Keywords: AISI 1006, heat treatment, tempering, absorption energy, hardness, and microstructure.

Penulis korespodensi

Email: n.herlinasari@unram.ac.id. 


\section{PENDAHULUAN}

Pembentukan lembaran baja untuk memperoleh bahan yang memiliki sifat kekuatan tinggi dan deformasi plastis untuk berbagai aplikasi dapat dilakukan dengan teknik perlakuan panas [1,2]. Secara umum, teknik ini diterapkan pada baja karbon rendah [3]. Hal ini dikarenakan baja karbon rendah memiliki keuletan yang tinggi dan mampu mesin, tetapi tidak tahan-aus. Baja AISI 1006 termasuk baja karbon rendah dengan kadar karbon sebesar $0.0721 \%$ [4]. Penambahan unsur tembaga pada baja dengan diikuti precipitation hardening telah diketahui dapat meningkatkan kekuatan tanpa menurunkan nilai keuletan. Kenaikan temperatur perlakuan larutan berbanding terbalik dengan nilai kekerasan. Nilai kekerasan cukup tinggi diperoleh pada suhu aging $450{ }^{\circ} \mathrm{C}$ [4]. Selain itu, Xinbo et al. [5] juga telah melaporkan perubahan tegangan aliran AISI 1006 dan AISI 5140 dalam rentang suhu tempa hangat (warm forging) secara sistematis melalui percobaan termo-mekanis. Efek suhu pembentukan, regangan efektif dan laju regangan telah dipertimbangkan. Hasil eksperimen mereka juga telah menawarkan dasar teoritis yang kuat untuk fondasi model matematika tegangan aliran, simulasi FEM. Kajian-kajian sebelumnya ini menunjukkan bahwa penyelidikan terkait efek suhu pemanasan dan tempering terhadap sifat mekanik dan strukturmikro dari baja AISI 1006 masih belum diselidiki.

Oleh karena itu, penelitian ini akan menyelidiki sifat mekanik dan strukturmikro dari baja AISI 1006 setelah dikenakan suhu pemanasan (perlakuan panas) dan tempering. Penelitian ini diharapkan dapat bermanfaat untuk pengembangan sifat baja dan informasi untuk kalangan industri.

\section{METODE}

\subsection{Bahan}

Baja karbon rendah AISI 1006. Komposisi kimia dari baja adalah Ferro (97.9\%), Carbon $(0.0654 \%)$, Silikon $(0.267 \%)$, Mangan $(0.636 \%)$, Sulfur $(0.047 \%)$, Molybdenum $(0.0389 \%$ dan Nikel $(0.240 \%)$. Selanjutnya pelat baja dibentuk dengan dan dipotong menurut dimensi standar internasional ASTM E23-56T untuk uji impak dan spesimen uji strukturmikro dan kekerasan vickers berukuran panjang x tebal yaitu $10 \mathrm{mmx} 25,4 \mathrm{~mm}$.

\subsection{Proses perlakuan panas}

Spesimen baja yang telah dibentuk sesuai standar diletakkan dalam tungku listrik. Variasi suhu pemanasan adalah $850^{\circ} \mathrm{C}, 900^{\circ} \mathrm{C}$ dan $950^{\circ} \mathrm{C}$ dengan waktu penahanan 60 menit. Peletakan spesimen di dalam tungku diperlihatkan dalam Gambar 1. Setelah pemanasan, spesimen didinginkan dalam tungku selama enam jam dengan tutup tungku terbuka. Jenis perlakuan spesimen dan kode penamaan diperlihatkan dalam Tabel 1.

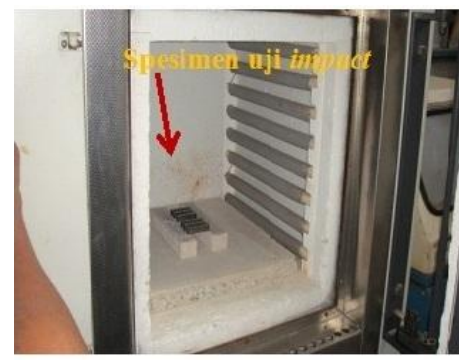

(a)

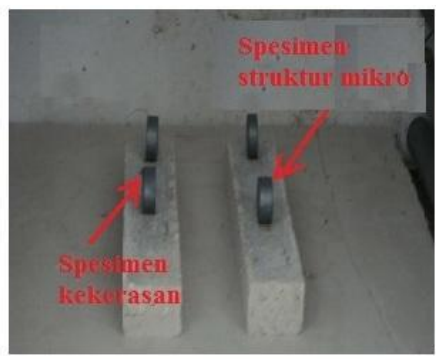

(b)

Gambar 1. Peletakan spesimen dalam tungku (a). Spesimen uji impak, (b). Uji kekerasan dan struktur mikro. 
Tabel 1. Kode penamaan spesimen uji

\begin{tabular}{ccc}
\hline No. & Spesimen & Kode \\
\hline 1. & Raw material & Raw \\
2. & $850{ }^{\circ} \mathrm{C}$ & SRA \\
3. & $900{ }^{\circ} \mathrm{C}$ & SRB \\
4. & $950{ }^{\circ} \mathrm{C}$ & SRC \\
5. & $850^{\circ} \mathrm{C}+{\text { Tempering } 200^{\circ} \mathrm{C}}^{\circ}$ & TKA \\
6. & $900^{\circ} \mathrm{C}+$ Tempering $200^{\circ} \mathrm{C}$ & TKB \\
7. & $950^{\circ} \mathrm{C}+{\text { Tempering } 200^{\circ} \mathrm{C}}^{-}$ & TKC \\
\hline
\end{tabular}

\subsection{Proses tempering}

Spesimen yang telah siap didalam tungku dipanaskan kembali sampai mencapai suhu 200 ${ }^{\circ} \mathrm{C}$ dengan waktu penahanan satu jam. Kemudian, proses pendinginan dilakukan didalam tungku dengan pintu terbuka dan mencapai suhu kamar.

Lebih lanjut, pengujian sifat mekanik dan struktur mikro dari spesimen telah dilakukan. Pengujian impak ditentukan dengan menggunakan mesin uji impact charpy, pengujian kekerasan dan struktur mikro dilakukan dengan menggunakan uji kekerasan Vickers dan mikroskop metalografi, berturut-turut.

\subsection{Pengujian mekanik}

\subsubsection{Pengujian kekuatan impak}

Nilai kekuatan impak dari spesimen diukur dengan menggunakan mesin uji impact Charpy. Semua spesimen baja untuk uji kekuatan dipersiapkan. Spesimen diletakkan pada anvil dengan posisi takikan membelakangi arah ayunan palu. Palu Charpy dan jarum penunjuk diposisikan berimpit pada sudut $156^{\circ}$. Kemudian, palu diayunkan membentur spesimen. Penentuan nilai energi serap dan harga kekuatan impak seperti ditunjukkan oleh Sari [6].

\subsubsection{Pengujian kekerasan}

Pengujian kekerasan dilakukan dengan menggunakan mesin uji kekerasan Vickers. Indentor piramida intan dipasang dan ditekan pada sudut $136^{\circ}$. Spesimen diletakkan dilandasan. Beban utama ditentukan sebesar 59,953 kg. Selanjutnya, menekan indentor pada titik yang akan diuji .

\subsection{Pengujian strukturmikro}

Semua spesimen uji struktur mikro di gosok dengan hand grinding dengan tingkat kehalusan 180, 600, 800,1000 dan 2000 mesh. Kemudian, dibersihkan menggunakan autosol. Pengetsaan dilakukan dengan larutan $\mathrm{HNO}_{3}$ sebesar 0,5\%; hal ini dimaksudkan untuk memperjelas struktur yang di amati dibawah mikroskop. Pembesaran dilakukan untuk mendapatkan kejelasan gambar.

\section{HASIL DAN PEMBAHASAN}

\subsection{Analisa energi serap dan harga kekuatan impak}

Gambar 2a menunjukkan bahwa peningkatan suhu pemanasan pada baja telah menurunkan nilai energi serap dan kekuatan dari spesimen baja. Dibandingkan dengan spesimen lainnya, nilai kekuatan dan energi serap dari spesimen SRA lebih tinggi yaitu sebesar 173.0 Joule dengan harga kekuatan impak sebesar 2,043 joule $/ \mathrm{mm}^{2}$ (lihat Gambar 2b); hal ini dikarenakan transformasi pearlit menjadi menjadi ferrite dan simentit; dengan naiknya suhu pemanasan, sehingga menghasilkan kemampuan serap dan kekuatan impak tinggi. Sebaliknya, kemampuan serap dan harga kekuatan impak turun pada spesimen (SRB dan 
SRC) dikarenakan transformasi ferrite menjadi pearlit dan simentit dengan batas butir yang lebih besar.

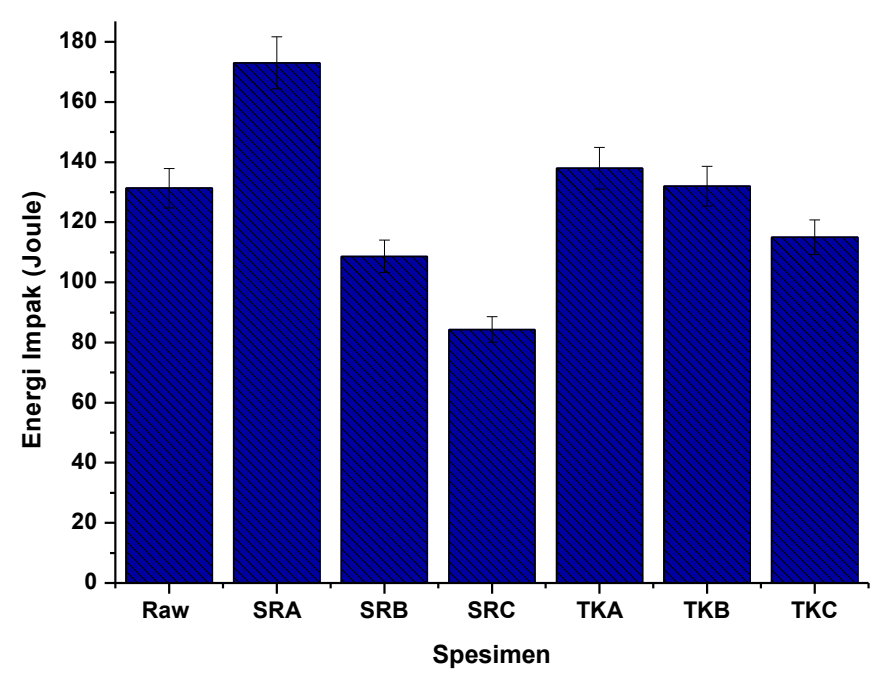

(a)

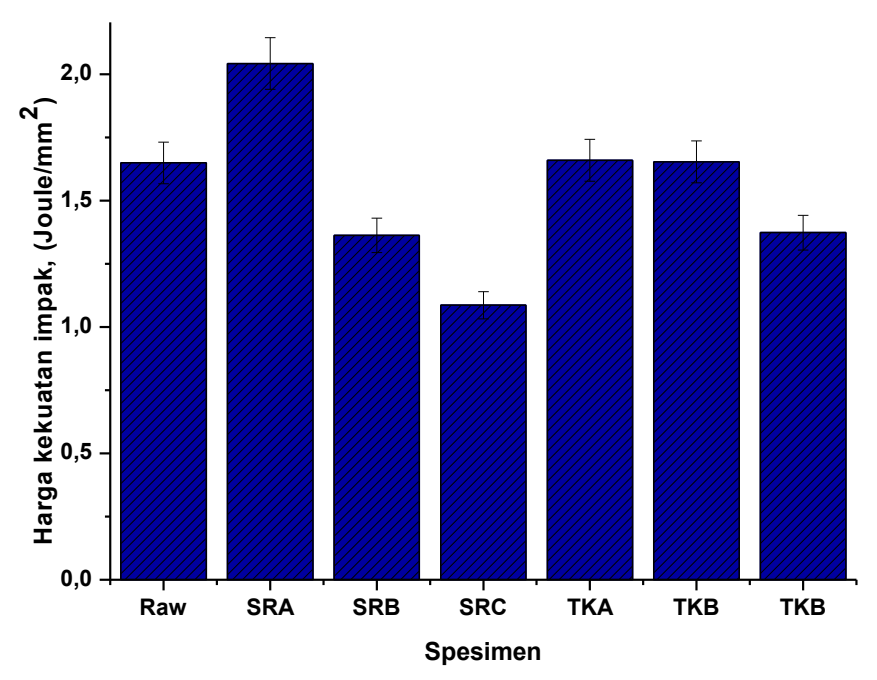

(b)

Gambar 2. a. Energi serap dari spesimen baja, b. Harga kekuatan impak dari spesimen baja hasil proses perlakuan panas dan tempering setelah dilakukan pengujian impak.

Lebih lanjut, Gambar 2a dan 2b juga menunjukkan bahwa secara umum, setelah dilakukan tempering pada suhu $200^{\circ} \mathrm{C}$, nilai energi serap dan harga kekuatan impak dari semua spesimen menurun; hal ini diduga terjadi karena austenit bertransformasi menjadi pearlit dan simentit dengan batas butir yang lebih lebar; sehingga kekuatan dan energi serap yang dihasilkan rendah. Selain itu, Muhamad [7] menyatakan bahwa pembentukan perubahan butir terjadi disebabkan oleh waktu penahanan. Pollack [8] juga melaporkan bahwa pemanasan baja pada suhu $800^{\circ} \mathrm{C}-1200^{\circ} \mathrm{C}$ dan didinginkan sampai $600^{\circ} \mathrm{C}$ akan membentuk fasa pearlit $($ alpha + cementit $)$. Sebagian fasa gamma terdistorsi menjadi fasa alpha jika 
pendinginan dilakukan sampai batas kritis $738^{\circ} \mathrm{C}$. Lebih lanjut, fasa ferrit bergabung di dalam perlit dan austenit bertransformasi menjadi karbida atau sementit ketika pendinginan dilakukan dibawah batas kritis.

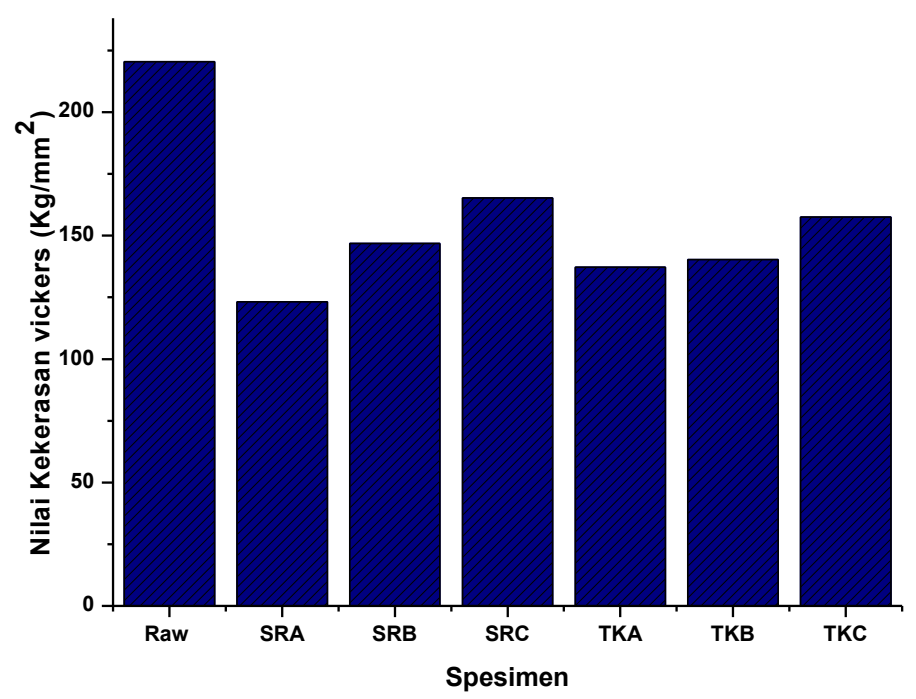

Gambar 3. Nilai kekerasan dari spesimen baja setelah perlakuan panas dan tempering

Struktur yang dihasilkan ini bersifat rapuh dan getas; sehingga energi serap dan kekuatan baja menjadi rendah. Hasil ini juga yang menjawab alasan mengapa nilai kekuatan dan energi serap dari spesimen setelah dipanaskan menjadi rendah. Hasil ini juga telah dikonfirmasi dengan strukturmikro dari baja pada pembahasan berikutnya.

\subsection{Analisa sifat kekerasan}

Gambar 3 memperlihatkan bahwa naiknya suhu pemanasan pada spesimen baja telah meningkatkan nilai rata-rata kekerasan dari baja. Spesimen SRC memiliki nilai kekerasan tertinggi $\left(220,45 \mathrm{~kg} / \mathrm{mm}^{2}\right)$ daripada spesimen SRA dan SRB. Angka kekerasan ini juga lebih tinggi jika dibandingkan dengan angka kekerasan Copperized-AISI 1006 (194,4 VHN) seperti yang telah dilaporkan oleh vicky et al.[4] dan Baja JIS SS 400 [9].

Gambar 3 juga menunjukkan bahwa setelah dilanjutkan tempering pada suhu $200^{\circ} \mathrm{C}$, nilai kekerasan semua spesimen (TKA, TKB dan TKC) juga menunjukkan peningkatan yang cukup siknifikan. Peningkatan ini diduga terjadi karena terbentuknya karbida pada ferrit; sehingga menghasilkan nilai kekerasan cukup tinggi. Keberadaan struktur tersebut meningkatkan kekerasan pada baja. Namun kenaikan ini masih lebih rendah daripada nilai kekerasan raw; disebabkan dominasi dari struktur pearlite dan ferrite; sehingga baja raw memiliki kekerasan yang tinggi.

\subsection{Analisa strukturmikro}

Gambar 4 menggambarkan bahwa pada spesimen raw, terdapat dua struktur yang mendominasi yaitu ferrite dan pearlite. Tetapi secara visual, jumlah struktur pearlite lebih banyak daripada struktur ferrite. Keberadaan kedua struktur ini yang menyebabkan sifat baja ini keras dan kuat.

Gambar 5, memperlihatkan strukturmikro pada spesimen SRA, SRB dan SRC. Perubahan fasa terlihat jelas pada struktur pearlit dan simentit dengan batas butir yang menjadi lebih besar (lihat dalam Gambar 5a, 5b dan 5c), Lebih lanjut, perubahan struktur ferrite menjadi pearlite dan simentit dengan batas butir yang lebih besar ditemukan pada spesimen SRC (lihat 


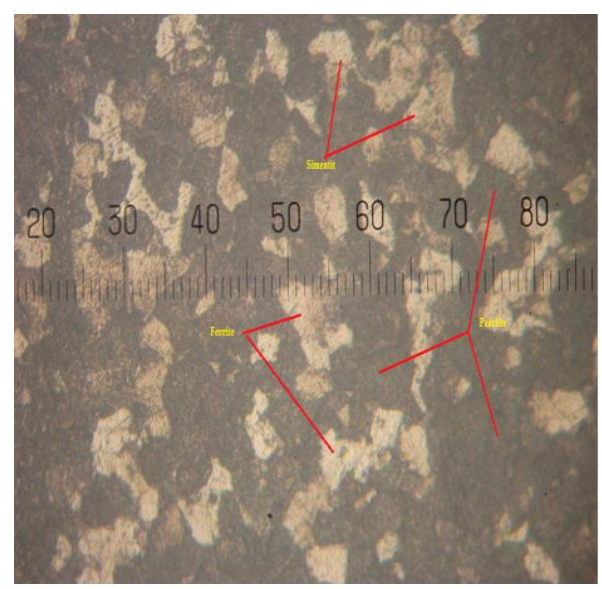

Gambar 4. Struktur mikro dari spesimen baja raw.
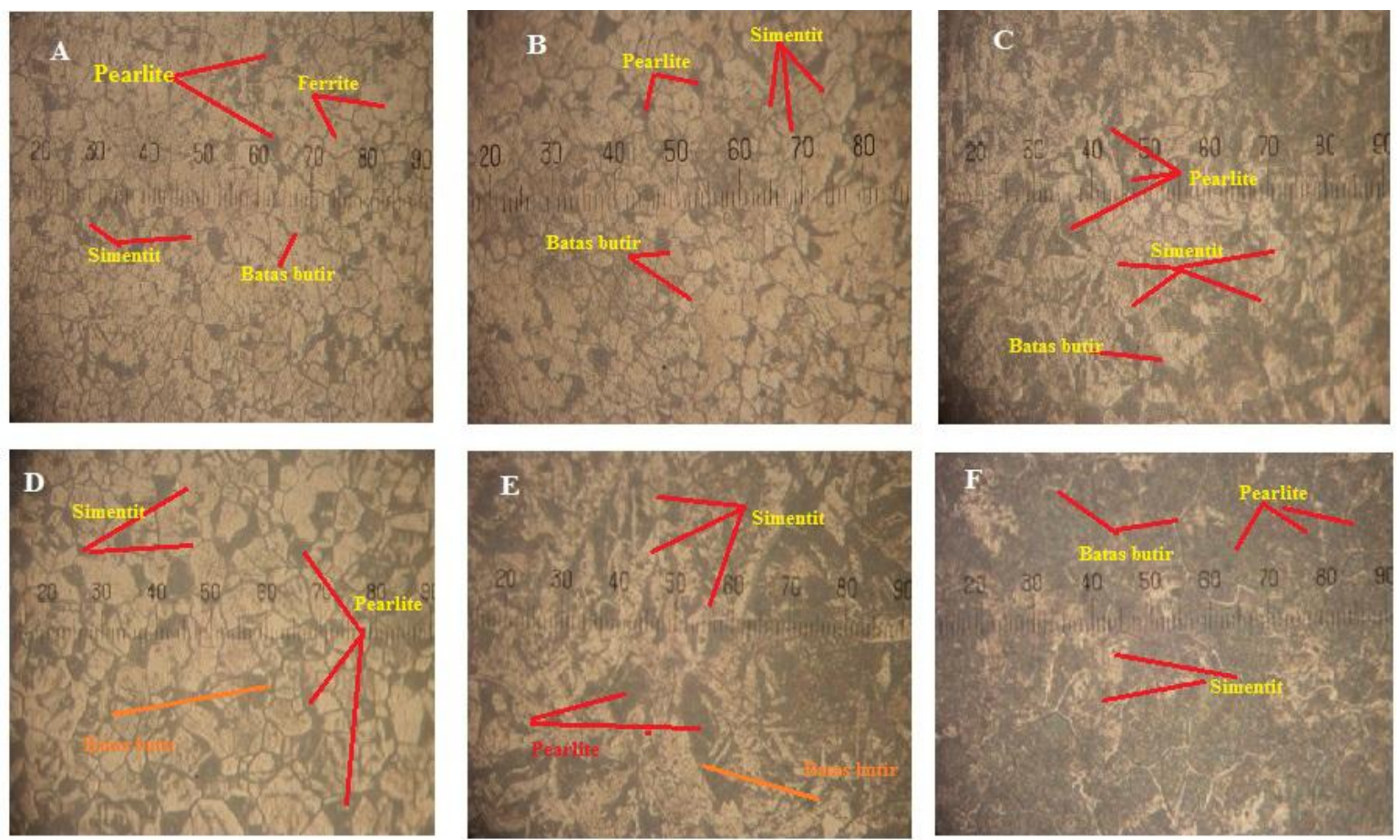

Gambar 5. Foto mikro a. SRA dan b. SRB dan c. SRC, d. TKA, e. TKB dan, f. TKC

Gambar 5c). Perubahan struktur terjadi dikarenakan kenaikan suhu pemanasan dan waktu pendinginan; maka sifat kekuatan dan kekerasan spesimen baja juga berubah.

Selanjutnya, efek tempering juga telah ditemukan pada strukturmikro dari spesimen baja. Gambar 5d menunjukkan adanya struktur simentite, pearlite dan ferrite, tetapi struktur ferrite lebih dominan daripada pearlite dengan batas butir yang lebih besar daripada spesimen SRA dan TKB.

Gambar 5e memperlihatkan adanya struktur simentit dan pearlit, dimana jumlah simentit lebih banyak daripada pearlit dengan batas butir yang lebih besar daripada spesimen SRB. Selanjutnya, spesimen TKC (lihat Gambar 5f) memperlihatkan adanya struktur pearlite dan simentit, dengan pearlite lebih dominan dan dengan batas butir yang lebih besar daripada spesimen TKA dan TKB. 


\section{SIMPULAN}

Analisa sifat-sifat dari baja AISI hasil proses perlakuan panas dan tempering telah dilakukan secara percobaan. Kenaikan suhu pemanasan dan perlakuan tempering telah menurunkan energi serap dan harga kekuatan impak dari baja. Sebaliknya, nilai kekerasan dari baja meningkat; tetapi nilai kekerasan tertinggi dimiliki oleh baja yang tidak diperlakukan panas; dikarenakan struktur ferrite dan pearlite yang jumlahnya lebih dominan dalam baja. Sedangkan, setelah dipanaskan perubahan struktur lebih dominan kearah simentit yang menunjukkan sifat dari baja yang kuat tapi getas. Perlu penelitian lebih lanjut tentang rekayasa logam menggunakan unsur kimia lain untuk meningkatkan kekuatan dan keuletan dari baja AISI 1006.

\section{DAFTAR PUSTAKA}

[1] N. H. Sari, Perlakuan panas pada baja karbon rendah; Efek media pendinginan terhadap sifat mekanik dan struktur mikro, Jurnal Teknik Mesin (JTM) Mercu Buana, Vol. 6, No. 4, 263-267, 2017. DOI: http://dx.doi.org/10.22441/jtm.v6i4.2091.

[2] Canale, L. C. F, Vatavuk, J, Totten, G. E., Introduction to Steel Heat Treatment. Elsevier Ltd, 2014.

[3] A. S. Darmawan, I. D. K. Okariawan, N. H. Sari, Pengaruh Variasi Kuat Arus Listrik Dan Waktu Proses Electroplating Terhadap Kekuatan Tarik, Kekerasan Dan Ketebalan Lapisan Pada Baja Karbon Rendah Dengan Krom. Dinamika Teknik Mesin, Volume 5 (2), 66-71, 2015.

[4] W. A. Vicky, Sutarsis, dan H, Purwaningsih, Pengaruh Temperatur Solution Treatment dan Aging terhadap Fasa Dan Kekerasan Copperized-AISI 1006. Jurnal Teknik ITS, Vol. 5, No. 2, 2016. ISSN 2337-3539 (2301-9271 Print).

[5] L. Xinbo, Z. Fubao, F. Jianhua, Z. Zhiliang, Research on the flow stress characteristics of AISI 1006 and AISI 5140 in the temperature range of warm forging by means of thermo-mechanical experiments, Journal of Materials Processing Technology, 122 (1), 38-44, 2002. https://doi.org/10.1016/S0924-136(02)00031-6.

[6] Sari, N. H., Material Teknik, Edisi 1, Deepublish, Yogyakarta, 2018. ISBN. 978-602453-671-8.

[7] Muhamad, D., Pengaruh Perbedaan Waktu Penahanan Suhu Stabil (Holding time) Terhadap Kekerasan Logam, Tugas Akhir Teknik Mesin, Universitas Negeri Semarang, Semarang. 1999.

[8] Pollack, H.W., Materials Science and Metallurgy, Edition 4, Prentice Hall, 1988. ISBN 10: 0835942872.

[9] S. Askar, Sinarep, N. H. Sari, Pengaruh Preheat dan Tempering Terhadap kekerasan dan Strukturmikro Hasil Pengelasan Baja JIS SS 400. Dinamika Teknik Mesin, Volume 3 (1), 16-25, 2013. ISSN: 2088-088X. 